\title{
Lower back pain after recently giving birth
}

\author{
Luis S. Beltran • Jenny T. Bencardino
}

Received: 11 July 2010 /Accepted: 14 October 2010 /Published online: 10 November 2010

(C) ISS 2010

\section{Part I}

A 33-year-old gravida 1, para 1 woman presented to the emergency room with severe lower back pain after recently giving birth. This was her first pregnancy, which was a spontaneous vaginal delivery at term, and she did not have any complications or prolonged labor at the time of the delivery. Radiography was performed at presentation. After conservative management and continued lower back pain, follow-up MRI and CT were obtained 6 months later Figs. 1, 2a-c and 3.

Disclosure The authors declare that they have no conflict of interest.
The diagnosis can be found at doi:10.1007/s00256-010-1061-7.

L. S. Beltran · J. T. Bencardino

NYU Hospital for Joint Diseases,

New York, NY, USA

\section{S. Beltran $(\bowtie)$}

Department of Radiology, NYU Hospital for Joint Diseases,

301 East 17th Street,

New York, NY 10003, USA

e-mail: Luis.Beltran@nyumc.org

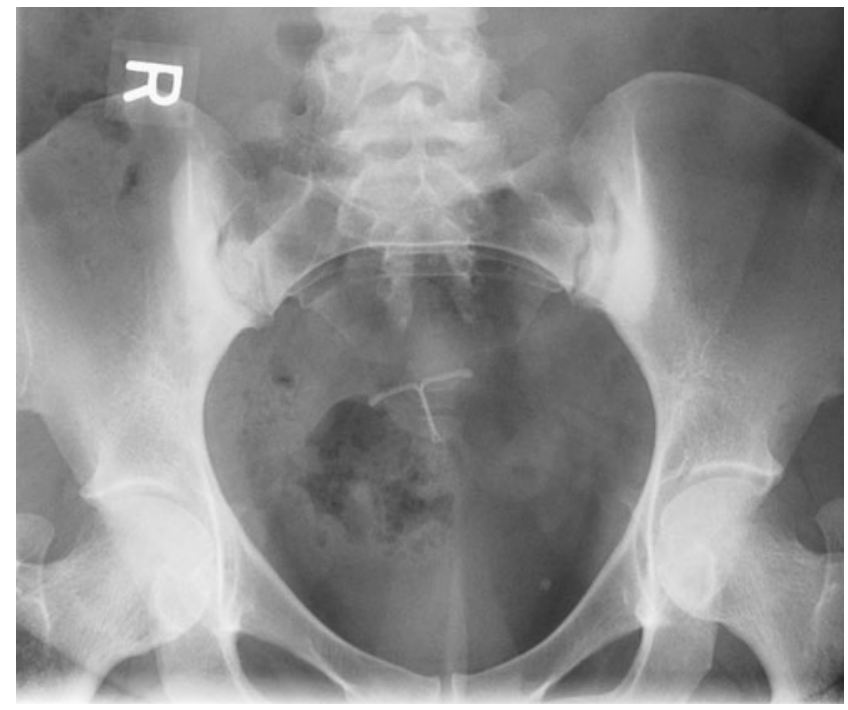

Fig. 1 Frontal AP radiograph of pelvis 

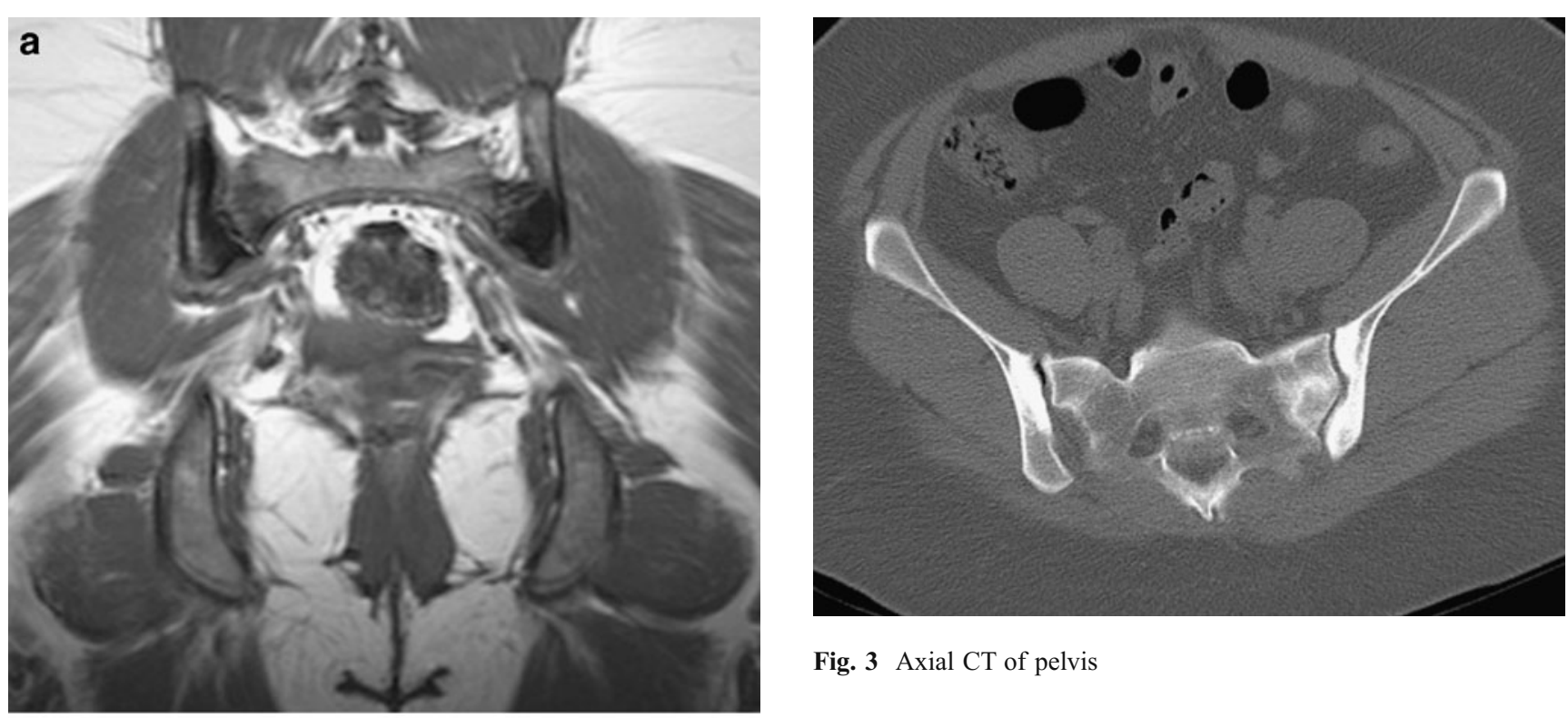

Fig. 3 Axial CT of pelvis
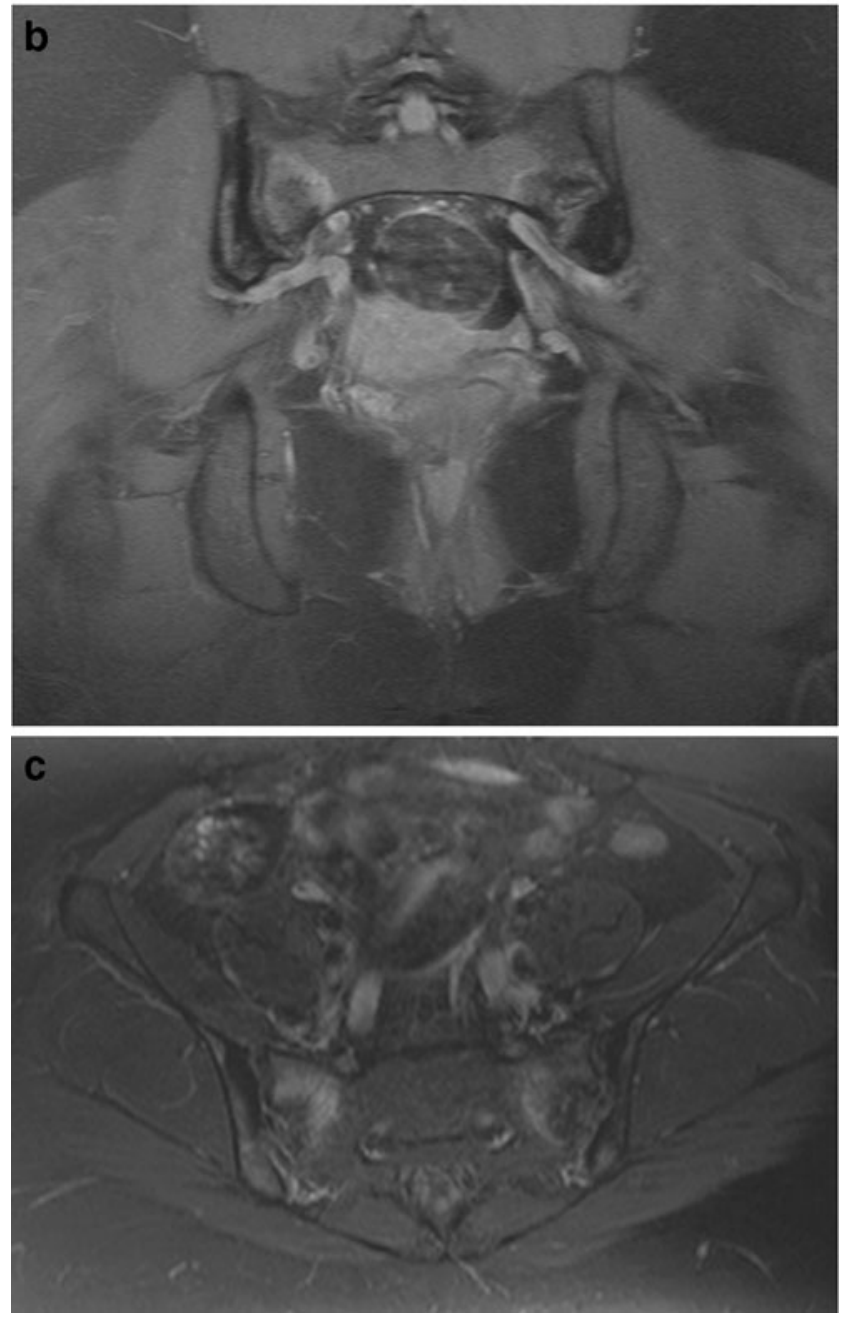

Fig. 2 a Coronal T1-weighted MRI of pelvis. b Coronal PD fatsuppressed MRI of pelvis. c Axial PD fat-suppressed MRI of pelvis 